\title{
Novosibirsk revisited 24 years on: chromosome polymorphism in the Novosibirsk population of the common shrew Sorex araneus L.
}

\author{
ANDREI V. POLYAKOV, NINA B. CHADOVA†, MARINA I. RODIONOVA, VICTOR V.

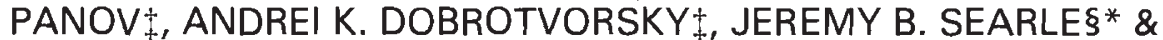 \\ PAVEL M. BORODIN \\ Institute of Cytology and Genetics, Novosibirsk, Russia, †University of Tomsk, Tomsk, Russia, ł/nstitute of \\ Systematics and Ecology of Animals, Novosibirsk, Russia and \$Department of Biology, University of York, PO Box \\ 373, York Y01 5YW, U.K.
}

\begin{abstract}
A Robertsonian fusion polymorphism in the common shrew (Sorex araneus L.), first described in Academgorodok near Novosibirsk (western Siberia) in 1970-72, was re-examined in 1994-95. The polymorphism in the 1970s involved chromosome arm combinations go, $\mathrm{jl}, \mathrm{mp}$ and $q r$, i.e. each of these combinations was present in both a metacentric and a twin-acrocentric state in the population at that time. The twin-acrocentric morph for go occurred at low frequency in 1970-72 and was not observed in 1994-95. The polymorphism for arm combinations $j l, m p$ and $q r$ was still observed in 1994-95 and there was no significant difference in metacentric/twin-acrocentric frequencies compared with the previous sample. This is the third well-documented example in which the chromosome polymorphism in the common shrew has been found to be unchanged over a period of $20+$ years. Although the polymorphism for $q r$ may be associated with a chromosomal hybrid zone with a cline centre $200 \mathrm{~km}$ away, there is no definitive explanation for the other polymorphisms.
\end{abstract}

Keywords: chromosome polymorphism, common shrew, Robertsonian fusion, Sorex araneus.

\section{Introduction}

Chromosome variation within species has attracted a great deal of attention in connection with questions of evolution and speciation (e.g. King, 1993). Sharman (1956) described variation in the karyotype of the common shrew (Sorex araneus L.), in one of the first studies on mammals using reliable colchicine-hypotonic squash techniques (Hsu, 1979). Since then there have been many further studies on the population cytogenetics of this small, abundant insectivore, often relating to fundamental aspects of chromosome evolution and the involvement of chromosomes in subdivision at the specific and subspecific levels (for recent compilations, see Hausser, 1991; Zima et al., 1994). Ancestrally, the common shrew is believed to have had a fully acrocentric autosomal complement (Wójcik \& Searle,

\footnotetext{
${ }^{*}$ Correspondence. E-mail: jbs3@york.ac.uk

Dedicated to the memory of Professor Sevil I. Radjabli.
}

1988; Volobouev, 1989), but varying combinations of these acrocentrics have been replaced by metacentrics in different parts of the northern Palaearctic distribution of the species. This is the result of the frequent occurrence of the Robertsonian fusion process, i.e. the joining together of a pair of nonhomologous acrocentric chromosomes at their centromeres to form a single metacentric chromosome. Thus, there is a variety of karyotypic races in the common shrew, which differ in their complement of acrocentric and metacentric chromosomes (see Wójcik, 1993 for a recent review). In the standard nomenclature for acrocentric (single-armed) and metacentric (bi-armed) chromosomes in the common shrew, each arm is labelled by a letter of the alphabet, with ' $a$ ' the largest arm and ' $u$ ' the smallest (Searle et al., 1991).

Robertsonian polymorphism, when a particular chromosome arm combination is present in both a twin-acrocentric and a metacentric state in a population, has been found in various parts of the range of 


\section{$X X X Y X_{\Lambda}^{V}$}

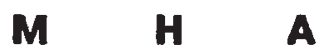

Fig. 1 The three karyotypes that can be recognized for each polymorphic arm combination in the common shrew: metacentric homozygotes $(\mathrm{M})$, heterozygotes $(\mathrm{H})$ and twin-acrocentric homozygotes (A).

the common shrew. For each polymorphic arm combination, three karyotypes can be recognized (Fig. 1): metacentric homozygotes, heterozygotes and twin-acrocentric homozygotes. There is a number of examples in which such polymorphism is associated with hybrid zones between karyotypic races (Searle, 1993) and other cases, e.g. on the island of Islay off Scotland (Ford \& Graham, 1964), where there are no known hybrid zones in the vicinity.

The Novosibirsk karyotypic race of the common shrew was first described by Král \& Radjabli (1974) on the basis of samples collected near Novosibirsk (western Siberia) in 1970 and 1972. In this population, they found polymorphism for four of the Novosibirsk chromosome arm combinations: go, jl, $\mathrm{mp}$ and $q r$. The aim of the present study was to re-examine the polymorphism after nearly a quarter of a century. Given the long history of population cytogenetics in the common shrew relative to other mammals, there is a particular opportunity to examine the long-term dynamics of chromosome polymorphisms in this species. This is one of the first studies to exploit this opportunity.

\section{Materials and methods}

The majority of common shrews used in the present study were collected from the Botanical Gardens of Academgorodok near Novosibirsk, Russian Federation (longitude: $83^{\circ} 06^{\prime} \mathrm{E}$, latitude: $54^{\circ} 49^{\prime} \mathrm{N}$ ). This is precisely the location used by Král \& Radjabli (1974) for their studies and represents a recreation area consisting of a variety of habitats (pine forest, aspen-birch mixed forest and shrub) criss-crossed by footpaths and roads. Within the Botanical Gardens, there is a permanent arrangement of pitfall traps for catching small mammals comprising four 50 -m-long trenches, each with five pitfalls. The trenches are variable distances apart, but none is closer than 500 m. For our study, 42 immature shrews were collected in these pitfalls during June-August 1994 and 15 adults during April-May 1995. No significant differences were found between the chromosomal characteristics of the two samples, so they were treated as a single data set.

All 57 individuals caught were karyotyped. Chromosome preparations were made from bone marrow by the method of Ford (1966), followed by G-band staining (Seabright, 1971).

The arrangement of pitfall traps in the Botanical Gardens has been in place since 1981, and data are available on the population dynamics of the common shrew for the whole period since then. To help interpret the chromosomal results, we made use of this information. The relative population density was scored as the number of animals trapped per pitfall per 100 days, based on daily trapping between May and September.

Also, to provide a broader geographical insight, one individual was collected near Tal'menka village, $120 \mathrm{~km}$ to the south of Academgorodok, on the right bank of the $\mathrm{Ob}^{\prime}$ (longitude: 83 $36^{\prime} \mathrm{E}$, latitude: $53^{\circ} 48^{\prime} \mathrm{N}$ ). This individual was karyotyped using the standard procedure.

\section{Results}

\section{Description of the Novosibirsk race}

The paper by Král \& Radjabli (1974) contained the first description of the Novosibirsk race. Although they used an outdated nomenclature, the idiogram of G-banded chromosomes they presented is very clear and permitted us to rename the chromosomes according to the new scheme (Searle et al., 1991). The description of the karyotype matches that of Aniskin \& Volobouev (1980, 1981), Král et al. (1981), Volobouev (1983), Aniskin \& Lukianova (1989) and Pack et al. (1993) and our recent observations. On the basis of these data, the Novosibirsk race is designated as follows:

$X X / X Y_{1} Y_{2}, a f, b c, h n, g / o, j / l, k i, m / p, g / r, t u$.

This standardized description (Searle et al., 1991; Hausser et al., 1994) acknowledges polymorphism of arm combinations $g o, j l, m p$ and $q r$ at Academgorodok and elsewhere in the Novosibirsk race, although for each arm combination the metacentric state predominates.

The Novosibirsk race appears to be restricted to western Siberia but extends considerable distances in all directions from our study site at Academgorodok. Volobouev (1983) and Aniskin \& Lukianova (1989) report the Novosibirsk race $200 \mathrm{~km}$ to the east of Academgorodok where it makes contact with the Tomsk race. Aniskin \& Volobouev (1981) found the race $340 \mathrm{~km}$ to the north near the village of Kolo- 
mino on the left bank of the Ob'. The race occurs $1120 \mathrm{~km}$ to the west of Academgorodok on the left bank of the Tobol river near Kurgan (Polyakov et al., 1997) and, in the present study, we were able to show that the race occurs $120 \mathrm{~km}$ south of Academgorodok. The individual from Tal'menka village was a female homozygous for all the Novosibirsk race metacentrics, except for $m p$, for which it was heterozygous. There is no indication that any other karyotypic race of common shrew is found within these geographical limits.

\section{Frequency analysis}

Our sample of 57 shrews from Academgorodok revealed polymorphism for three chromosomes: $j l$, $m p$ and $q r$, with the metacentric morph more frequent than the homologous twin-acrocentric morph in all cases (Table 1). Considering these polymorphic arm combinations, all possible karyotypes (metacentric homozygotes, heterozygotes and twinacrocentric homozygotes; Fig. 1) were observed for $m p$ and $q r$, whereas only metacentric homozygotes and heterozygotes were found for $j l$. Although Král \& Radjabli (1974) found one individual heterozygous for arm combination go among their sample of 29 individuals, all the animals we examined were metacentric homozygotes. For both our data and those of Král \& Radjabli (1974), there was no significant deviation from the Hardy-Weinberg expectation of karyotype frequency for any arm combination.

Not only did we find the same polymorphisms as Král \& Radjabli (1974), but also the metacentric frequencies were almost identical for all chromosomes except $m p$ (Table 1). For $m p$, we found a 9 per cent higher frequency of the twin-acrocentric morph than Král \& Radjabli (1974); however, the difference in frequencies is not statistically significant $\left(\chi_{1}^{2}=2.58, P>0.05\right)$.

Table 1 Frequency of the metacentric morph for each polymorphic arm combination in common shrews collected at Academgorodok by Král \& Radjabli (1974) and ourselves

\begin{tabular}{lcc}
\hline Arm combination & $1970-72(n=29)$ & $1994-95(n=57)$ \\
\hline go & 0.98 & 1.00 \\
$j l$ & 0.93 & 0.97 \\
$m p$ & 0.97 & 0.88 \\
$q r$ & 0.83 & 0.84 \\
\hline
\end{tabular}

Frequency of twin-acrocentric morph $=1-$ frequency of metacentric morph.

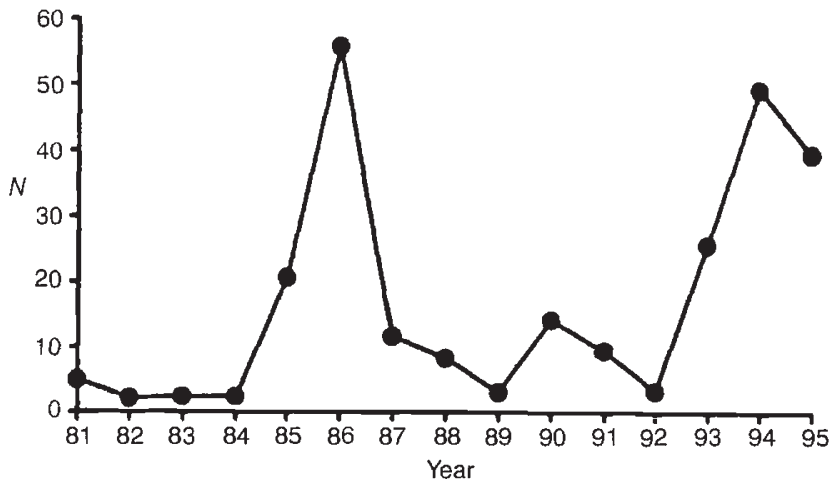

Fig. 2 Fluctuation in the relative population density of common shrews recorded at Academgorodok. $N$, number of animals trapped per pitfall per 100 days.

\section{Population dynamics}

Figure 2 shows the variation in relative population density of the common shrew in the Botanical Gardens of Academgorodok. The data indicate that, over the period of observation, the population density varied widely. The densities recorded in 1986 and 1994 were more than 10 times higher than those found in 1982-84, 1989 and 1992.

\section{Discussion}

Although chromosome polymorphisms have been detected in populations of a variety of species, few attempts have been made to determine the degree of temporal stability. Before the present study, there had been two detailed longitudinal studies of Robertsonian polymorphism in the common shrew.

First, Searle (1986) re-examined a polymorphism in the vicinity of Oxford, UK, 25 years after it was first described by Ford and co-workers (Sharman, 1956; Ford et al., 1957; Ford \& Hamerton, 1970). In this case, the mean chromosome number recorded at two polymorphic sites in the mid-1950s was consistent with the more recent data. However, a precise comparison of the frequencies of polymorphic chromosomes was impossible owing to uncertainty of identification of some arm combinations in the earlier study (Searle, 1986).

Secondly, Fedyk (1980, 1982) and Wójcik (1991) have studied the chromosome polymorphism in common shrews from Bialowieza, Poland. The data collected in 1968, 1969-70, 1971, 1972 and 1974 demonstrated a gradual decrease in the overall frequency of the twin-acrocentric morphs of three polymorphic arm combinations, suggesting possible 
transience of the polymorphism. However, later data did not support this interpretation. In 1977, the overall frequency of the twin-acrocentrics was the same as in 1969-70 and this frequency remained stable in 1983, 1989 and 1990 (Fedyk, 1982; Wójcik, 1991).

Our data demonstrate that in the population at Academgorodok, near Novosibirsk in western Siberia, a stable Robertsonian polymorphism has persisted over a long period of time. Král \& Radjabli (1974) found a polymorphism for four chromosomes: go, $j l, m p$ and $q r$. Twenty-four years later, we demonstrated that three of them ( $j l, m p$ and $q r$ ) remained polymorphic in the same population. We did not find the twin-acrocentric morph of $g, o$, but even in 1970-72 it was very rare (Table 1). None of the other three twin-acrocentric morphs has undergone significant changes in its frequency over this period of time (Table 1). Taking the four polymorphic arm combinations, the overall frequency of the twin-acrocentric morphs was 0.073 in $1970-72$ and 0.077 in 1994-95.

Thus, there have now been three temporal studies on Robertsonian chromosomal polymorphism in the common shrew in areas that are geographically remote from each other (in Britain, Poland and Siberia). All have demonstrated remarkable stability of the polymorphism.

The stable polymorphism in the Oxford area can be explained by the fact that the samples collected by Ford and co-workers in the 1950s (Ford et al., 1957) were taken from sites close to the centre of a hybrid zone between the Oxford and Hermitage chromosomal races (Searle, 1986). Hybrid zones are often likely to remain stable in their characteristics for hundreds or thousands of years (Barton \& Hewitt, 1985). We believe that we have reasonably accurate information on the distance between Academgorodok and the nearest hybrid zone; the Novosibirsk race is now well surveyed, with data based on G-banded chromosomes available from 19 well-spaced sites (Aniskin \& Volobouev, 1980, 1981; Král et al., 1981; Volobouev, 1983; Aniskin \& Lukianova, 1989; Polyakov et al., 1997; A. V. Polyakov, unpublished data). The nearest known location for a hybrid zone (the contact with the Tomsk race) is 200 $\mathrm{km}$ to the east at Krekovo (Volobouev, 1983; Aniskin \& Lukianova, 1989), and it is likely that the zone bends round to maintain a similar distance to the south. There do not appear to be any contacts close to Academgorodok to the north or east.

It is unlikely that the polymorphisms for arm combinations go, $j l$ and $m p$ at Academgorodok relate to the presence of the Tomsk race $200 \mathrm{~km}$ or so away. Both races are characterized by $j l$ in a metacentric state and, even at the hybrid zone site of Krekovo, the frequency of $g o$ and $m p$ among the 138 Novosibirsk race individuals was as high as 0.94 and 0.97 , respectively (Volobouev, 1983). A high frequency of acrocentrics $g, o$ and $m, p$ is not characteristic of either the hybrid zone or the Tomsk race. On the other hand, the Tomsk race is characterized by acrocentrics $q$ and $r$, so the polymorphism for arm combination $q r$ at Academgorodok may reflect the occurrence of a wide cline for this arm combination centred on the Novosibirsk-Tomsk hybrid zone. Polymorphism for one arm combination was recorded in a small sample $60 \mathrm{~km}$ from the centre of the Oxford-Hermitage hybrid zone (Searle, 1986), so it is not inconceivable for introgression of chromosomes from the Tomsk race to penetrate 200 $\mathrm{km}$ into the Novosibirsk race.

Given the known occurrence of Robertsonian polymorphism in association with chromosomal hybrid zones in the common shrew, including probably the polymorphism for $q r$ at Academgorodok, it could be that the polymorphisms for go, $j l$ and $m p$ represent the 'ghost of hybridization past'. Even if polymorphism for these elements does not relate to current hybridization, it may relate to past hybridization events that are no longer recognizable as a result of range changes. Thus, the acrocentrics $j, l$ and $g, o$ and $m, p$ may be viewed as neutral or slightly deleterious variants destined for extinction (there is probably a degree of disadvantage, albeit very small, associated with these twin-acrocentric morphs in the heterozygous state: see Searle, 1993). The population dynamics found at Academgorodok would appear to favour a rapid fixation of the metacentrics $g o, j l$ and $m p$, given the tendency (revealed in 1982-84, 1989 and 1992; Fig. 2) for apparently severe population bottlenecks. The lack of observed fixation of the metacentrics may reflect the fact that the population of common shrews around Academgorodok is, in reality, rather extensive; more data are required on dispersal and the size of the area of suitable habitat extending beyond the trap lines.

It is also conceivable that the Robertsonian polymorphisms at Academgorodok are somehow 'maintained' by natural selection. One possibility, heterozygous advantage, was originally suggested by Ford \& Hamerton (1970). However, as already mentioned, there is, if anything, an expectation for heterozygous disadvantage associated with chromosomal rearrangements because of meiotic errors (Searle, 1993). Also, there is no support from karyotype frequencies for a model of heterozygous advantage. In all three long-term studies of chromosomal 
polymorphism in the common shrew, including our study at Academgorodok, there is generally a very close fit between observed karyotype frequencies and the Hardy-Weinberg expectation for all polymorphic arm combinations (our data; Král \& Radjabli, 1974; Fedyk, 1980; Searle, 1986; Wójcik, 1991).

Wójcik (1991) suggested that the stable polymorphism observed in common shrews at Bialowieza is related to environmental heterogeneity. In samples collected during 1989-90, he found significant differences in the frequency of the twin-acrocentric morph for one arm combination between habitat types. As in our study, there is no evidence for close proximity of a hybrid zone. Some sort of adaptive significance cannot be ruled out as an explanation of the polymorphism at Academgorodok, but we did not test for variation in morph frequency between habitat types.

Clearly, it is uncertain whether or not natural selection needs to be invoked to explain the stability of the Robertsonian polymorphism in the common shrew at Academgorodok. There is a requirement for further detailed, ecologically orientated studies. Also, for the polymorphisms at both Bialowieza and Academgorodok, it would be worthwhile to expand the study of chromosomal variation over a wide geographical area; it was this approach that revealed the cause of the polymorphism near Oxford (Searle, 1986). The understanding of these well-documented stable polymorphisms is an important part of our appreciation of the extraordinary degree of Robertsonian variation in the common shrew.

\section{Acknowledgements}

The study was supported in part by INTAS grant 93-1463, ISF grant NPR300 and the Russian Fund for Fundamental Research.

\section{References}

ANISKIN, V. M. AND LUKIANOVA, I. V. 1989. A new chromosome race and the analysis of a hybridization zone of two karyoforms of Sorex araneus (Insectivora, Soricidae). Dokl. Akad. Nauk SSSR, 309, 1260-1262 (in Russian).

ANiskin, V. M. ANd volobouev, v. T. 1980. Chromosomal polymorphism in Siberian populations of the shrews of araneus-arcticus complex (Insectivora, Soricidae). I. Chaldeevo and Bericul's populations of common shrew Sorex araneus L. (1758). Genetika, 16, 1044-1051 (in Russian).

ANISKIN, V. M. AND volobouev, v. T. 1981. Chromosomal polymorphism in Siberian populations of the shrews of araneus-arcticus complex (Insectivora, Soricidae). III. Three chromosome forms of common shrew Sorex araneus, L. (1758). Genetika, 17, 1784-1791 (in Russian).

BARTON, N. H. AND hewitT, G. M. 1985. Analysis of hybrid zones. Ann. Rev. Ecol. Syst., 16, 113-148.

FEDYK, s. 1980. Chromosome polymorphism in a population of Sorex araneus L. at Bialowieza. Folia Biol., 28 , 83-120.

FEDYK, s. 1982. Further studies on chromosome polymorphism of the common shrew. Acta Theriol., 27, 149-153

FORD, C. E. 1966. The use of chromosome markers. In: Micklem, H. S. and Loutit, J. F. (eds) Tissue Grafting and Radiation, pp. 197-206. Academic Press, New York.

FORD, C. E. AND HAMERTON, J. L. 1970. Chromosome polymorphism in the common shrew, Sorex araneus. Symp. Zool. Soc. Lond., 26, 223-236.

FORD, C. E., HAMERTON, J. L. AND SHARMAN, G. B. 1957. Chromosome polymorphism in the common shrew. Nature, 180, 392-393.

FORD, P. J. AND GRAHAM, C. F. 1964. The chromosome number in the common shrew, Sorex araneus L. Bull. Mammal Soc. Br. Is., 22, 10-11.

HAusser, J. (ed.) 1991. The Cytogenetics of the Sorex araneus Group and Related Topics. Proceedings of ISACC's Second International Meeting. Mém. Soc. Vaud. Sci. Nat., 19, 1-151.

HAUSSER, J., FEDYK, S., FREDGA, K., SEARLE, J. B., VOLOBOUEV, V. T., WÓJCIK, J. M. AND ZIMA, J. 1994. Definition and nomenclature of the chromosome races of Sorex araneus. In: Zima, J., Searle, J. B. and Macholán, M. (eds) The Cytogenetics of the Sorex araneus Group and Related Topics, pp. 1-9. Proceedings of ISACC's Third International Meeting. Folia Zool., 43 (suppl. 1), 1-9.

HSU, T. C. 1979. Human and Mammalian Cytogenetics: an Historical Perspective. Springer-Verlag, New York.

K1NG, M. 1993. Species Evolution: the Role of Chromosome Change. Cambridge University Press, Cambridge.

KRÁl, B. AND RADJABLI, S. 1. 1974. Banding patterns and Robertsonian fusion in the Western Siberian population of Sorex araneus (Insectivora, Soricidae). Zool. Listy, 23, 217-227.

KRÁL, B., ANISKIN, V. M. AND VOlobOUEV, V. T. 1981. Karyotype variability in Siberian populations of Sorex araneus (Insectivora, Soricidae). Folia Zool, 30, 23-37.

PACK, S. D., BORODIN, P. M., SEROV, O. L. AND SEARLE, J. B. 1993. The $X$-autosome translocation in the common shrew (Sorex araneus L.): late replication in female somatic cells and pairing in male meiosis. Chromosoma, 102, 355-360.

POLYAKOV, A. V., BORODIN, P. M., LUKÁCOVÁ, L., SEARLE, J. B. AND ZIMA, J. 1997. The hypothetical Old-Northern chromosome race of Sorex araneus found in the Ural Mts. Ann. Zoo. Fenn., (in press).

SEABRIGHT, M. 1971. A rapid banding technique for human chromosomes. Lancet, ii, 971-972. 
SEARLE, J. B. 1986. Factors responsible for a karyotypic polymorphism in the common shrew, Sorex araneus. Proc. R. Soc. B, 229, 277-298.

SEARLE, J. B. 1993. Chromosomal hybrid zones in eutherian mammals. In: Harrison, R. G. (ed.) Hybrid Zones and the Evolutionary Process, pp. 309-353. Oxford University Press, New York.

SEARLE, J. B., FEDYK, S., FREDGA, K., HAUSSER, J. AND VOlobouEV, V. T. 1991. Nomenclature for the chromosomes of the common shrew (Sorex araneus). Mém. Soc. Vaud. Sci. Nat., 19, 13-22.

SHARMAN, G. B. 1956. Chromosomes of the common shrew. Nature, 177, 941-942.

volobouev, v. т. 1983. Les types du polymorphisme chromosomique et leur rôle evolutif chez les mammiferes (Insectivora, Rodentia et Carnivora). Thesis, l'Université Pierre et Marie Curie, Paris. volobouev, v. T. 1989. Phylogenetic relationships of the Sorex araneus-arcticus complex (Insectivora, Soricidae) based on high-resolution chromosome analysis. $J$. Hered., 80, 284-290.

wóJCIK, J. M. 1991. Chromosomal polymorphism in the common shrew Sorex araneus and its adaptive significance. Mém. Soc. Vaud. Sci. Nat., 19, 51-62.

WóJCIK, J. M. 1993. Chromosome races of the common shrew Sorex araneus in Poland: a model of karyotype evolution. Acta Theriol, , 38, 315-338.

WóJCIK, J. M. AND SEARLE, J. B. 1988. The chromosome complement of Sorex granarius - the ancestral karyotype of the common shrew (Sorex araneus)? Heredity, 61, 225-229.

ZIMA, J., SEARLE, J. B. AND MACHOLÁN, M. (eds) 1994. The Cytogenetics of the Sorex araneus Group and Related Topics. Proceedings of ISACC's Third International Meeting. Folia Zool., 43 (suppl. 1), 116 pp. 